\title{
Retraction Note to: Fully biobased epoxy from isosorbide diglycidyl ether cured by biobased curing agents with enhanced properties
}

\author{
Ruixue Chang • Jianglei Qin • Jungang Gao
}

Published online: 15 March 2015

(C) Springer Science+Business Media Dordrecht 2015

Retraction to: J Polym Res (2014) 21:501

DOI 10.1007/s10965-014-0501-9

The article "Fully biobased epoxy from isosorbide diglycidyl ether cured by biobased curing agents with enhanced properties" (Ruixue Chang, Jianglei Qin, Jungang Gao, 12 June 2014) is hereby retracted at the request of the authors. The results presented in this work were obtained by Dr Qin's former colleagues at Washington State University and were included without their knowledge or permission.

The online version of the original article can be found at http://dx.doi.org/ 10.1007/s10965-014-0501-9.

R. Chang $\cdot$ J. Qin $(\bowtie) \cdot J$. Gao

College of Chemistry and Environment Science, Hebei University,

Baoding 071002, People's Republic of China

e-mail: qinhbu@iccas.ac.cn 